\title{
Stripping of Membrane
}

National Cancer Institute

\section{Source}

National Cancer Institute. Stripping of Membrane. NCI Thesaurus. Code C92890.

An intervention during labor and delivery, of gently sweeping the amniotic membrane to separate it from the attachment to the lower uterine segment. 